\title{
Can earthquakes lead to delayed avalanche release?
}

\section{Other Conference Item}

Author(s):

Puzrin, Alexander (D); Faug, Thierry; Einav, Itai

Publication date:

2020-05

Permanent link:

https://doi.org/10.3929/ethz-b-000462101

\section{Rights / license:}

Creative Commons Attribution 4.0 International

\section{Originally published in:}

EGUsphere, https://doi.org/10.5194/egusphere-egu2020-22530 


\title{
EGU2020-22530
}

https://doi.org/10.5194/egusphere-egu2020-22530

EGU General Assembly 2020

(c) Author(s) 2021. This work is distributed under

the Creative Commons Attribution 4.0 License.

\section{Can earthquakes lead to delayed avalanche release?}

\author{
Alexander M. Puzrin ${ }^{1}$, Thierry Faug ${ }^{2}$, and Itai Einav ${ }^{3}$ \\ ${ }^{1}$ Institute for Geotechnical Engineering, ETH Zurich,Stefano-Franscini-Platz 5, 8093 Zurich, Switzerland \\ (alexander.puzrin@igt.baug.ethz.ch) \\ ${ }^{2}$ Université Grenoble Alpes, INRAE, UR ETNA, 2 rue de la PapeterieBP 76, 38402 Saint-Martin d'Hères, France \\ (thierry.faug@inrae.fr) \\ ${ }^{3}$ Particles and Grains Laboratory, School of Civil Engineering, TheUniversity of Sydney, Sydney, New South Wales 2006, \\ Australia (itai.einav@sydney.edu.au)
}

Strong earthquakes often trigger snow avalanches, sometimes with observable delays. Most existing models assume that snow slab avalanches happen simulatenously during or immediatly after their triggering. Therefore, they cannot explain the plausibility of delayed avalanches that are released minutes to hours after a quake. Resolving this shortcoming is critical for improving safety, as emphasized by deadly delayed avalanches in Western Himalaya and, most recently, by the devastating Rigopiano avalanche in Italy's Abruzzo region, which occurred more than 30 min after the last in a series of major quakes on 18 January 2017. This work establishes the basic mechanism of delays in earthquake-induced avalanche release using a novel analytical model that yields failure scenarios consistent with the Western Himalaya and Rigopiano cases. The mechanism arises from the interplay between creep, strain softening and strain-rate sensitivity of snow, which drive the growth of a basal shear fracture. Our results imply that earthquake-delayed avalanches are rare, yet possible, and could lead to significant damade, especially in long milder slopes. The generality of the model formulation opens a new avenue for exploring other questions related to natural slab avalanche release. 